\title{
Characterization and in silico Mutagenic Assessment of a New Betahistine Degradation Impurity
}

\author{
Murilo B. M. de Mello, ${ }^{a, \#}$ Antonio A. F. de Oliveira, ${ }^{b, \#}$ Caroline L. de Oliveira, ${ }^{b}$ \\ Mariah A. Ultramari, ${ }^{b}$ Fernando H. S. Gama, ${ }^{b}$ Alessandra Mascarello, ${ }^{b}$ \\ Cristiano R. W. Guimarães, ${ }^{b}$ Miller N. de Freitas, ${ }^{b}$ Carlos E. Cunha, ${ }^{c}$ Tiago C. Lourenço, ${ }^{d}$ \\ Fernanda P. Ferreira, ${ }^{e}$ João L. C. Lopes ${ }^{a, f}$ and Giuliano C. Clososki ${ }^{\circledR} *, a$ \\ ${ }^{a}$ Núcleo de Pesquisa em Produtos Naturais e Sintéticos (NPPNS), \\ Faculdade de Ciências Farmacêuticas de Ribeirão Preto, Universidade de São Paulo, \\ Av. Café s/n, 14040-903 Ribeirão Preto-SP, Brazil \\ ${ }^{b}$ Aché Laboratórios Farmacêuticos S.A., Rodovia Presidente Dutra, km 222,2, Porto da Igreja, \\ 07034-904 Guarulhos-SP, Brazil
}

${ }^{c}$ Lhasa Limited, Granary Wharf House, 2 Canal Wharf, LS11 5PS Leeds, UK

${ }^{d}$ Apex Science, Avenida Marechal Rondon, 2148, 13070-173 Campinas-SP, Brazil

${ }^{e}$ Lychnoflora Pesquisa e Desenvolvimento em Produtos Naturais, Rua Ângelo Mestriner, 263, Vila Virgínia, 14030-090 Ribeirão Preto-SP, Brazil

${ }^{f}$ Avita Produtos Químicos e Farmacêuticos, Av. Dra. Nadir Aguiar 1805, Mod. 27 B, Jardim Dr. Paulo Gomes Romeo, 14056-680 Ribeirão Preto-SP, Brazil

\begin{abstract}
Currently, the pharmaceutical industry devotes great attention to drug degradation products because these compounds can offer risks to patients. A previous degradation study of betahistine ( $N$ - $\alpha$-methyl-2-pyridylethylamine) conducted under different stress conditions detected three main impurities named A, B and C. Degradation products were analyzed by high-resolution mass spectrometry in electrospray source and time of flight analyzer (ESI-TOF) and nuclear magnetic resonance (NMR). Impurity mutagenicity was evaluated by Derek Nexus and Sarah Nexus softwares. Liquid chromatography hyphenate with tandem mass spectrometry (LC-MS/MS) analysis of the betahistine forced degradation sample indicated the presence of a new impurity, which was named impurity C1. 2D NMR experiments allowed the complete structural characterization of the new entity. The active pharmaceutical ingredient and degradation impurities were classified as inactive in the in silico mutagenic studies. Systematic investigation of a forced degradation sample led to the characterization of a new betahistine impurity. The in silico mutagenicity study of the betahistine degradation impurities may be useful in the risk assessment of the drug products.
\end{abstract}

Keywords: betahistine, drug stability, drug impurities, forced-degradation studies

\section{Introduction}

Betahistine (1) ( $N$ - $\alpha$-methyl-2-pyridylethylamine), a histamine (2) analog (Figure 1), has long been reported as an effective drug for the treatment of vascular problems such as Ménière's disease, ${ }^{1-3}$ an inner ear disorder that is clinically characterized by recurrent vertigo, tinnitus, and

*e-mail: gclososki@fcfrp.usp.br

"Murilo B. M. de Mello and Antonio A. F. de Oliveira had contributed equality for this work. hearing loss episodes and which is linked to endolymphatic drops. ${ }^{4}$ Ménière's disease is the second most common cause of peripheral vestibular vertigo, which can affect approximately $0.2 \%$ of the world population. ${ }^{5,6}$ Betahistine also exerts a cerebral and peripheral vasodilation effect because it increases the blood flow ${ }^{7,8}$ and improves the microcirculation of the internal auditory, cochlear, and vestibular systems. ${ }^{9-11}$ The betahistine mechanism of action involves interactions with $\mathrm{H} 1$ and $\mathrm{H} 3$ receptors, ${ }^{12}$ which inhibit the vestibular nucleus firing activity. Many 
controlled clinical studies involving vertigo patients have demonstrated its therapeutic effect. ${ }^{2,12}$

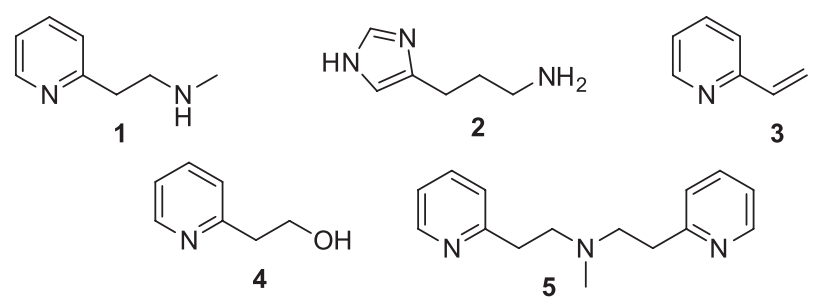

Figure 1. Betahistine (1), histamine (2), and betahistine-related impurities $\mathbf{3}, \mathbf{4}$, and $\mathbf{5}$.

Nowadays, the pharmaceutical industry devotes great attention to drug degradation products because these compounds can offer risks to patients. ${ }^{13}$ Factors like oxygen, heat, and light, among others, can mediate molecular changes in the drug structure. ${ }^{14-19}$ These factors may induce specific reactions such as oxidation and hydrolysis to produce impurities..$^{20}$ The presence of even small amounts of a new compound may influence the pharmaceutical product efficacy and safety. ${ }^{21}$ In addition to the methods from official compendiums, for instance British Pharmacopeia (BP) and the United States Pharmacopeia (USP), some internationally agreed recommendations, such as those from International Conference on Harmonization (ICH), focus on profiling drug impurities qualitatively and quantitatively. ${ }^{22}$ The guidelines ICH Q3A (R2) ${ }^{23}$ and Q3B (R2) ${ }^{24}$ consider impurities in new drug substances and new drug products, respectively, whilst ICH Q3C (R6) ${ }^{25}$ deals with residual solvents. These guidelines highlight the relevance to establishing safe thresholds for unwanted chemicals in medicines in such a way that producers create strategies to eliminate or at least to control the impurities below that levels.

Currently, the United States and the British Pharmacopeias ${ }^{26}$ cite structures $\mathbf{3}, \mathbf{4}$, and $\mathbf{5}$, also called impurities A, B, and C, respectively, as betahistine-related impurities (Figure 1). A previous betahistine degradation study conducted under different stress conditions detected these impurities. ${ }^{27}$

Liquid chromatography coupled to electrospray ionization mass spectrometry (LC-ESI-MS) is a powerful methodology to characterize impurities and degradation products from the chemical ${ }^{28}$ and the pharmaceutical ${ }^{26}$ industries. Over the last decade, our group has made efforts to characterize ionization ${ }^{29}$ and gas-phase decomposition reactions by means of the electrospray source $(\mathrm{ESI})^{30}$ in order to contribute to the structural elucidation of small molecules.

Interestingly, our preliminary LC-MS/MS analysis of forced betahistine sample (hydrochloride tablets) degradation indicated the presence of an unknown impurity. This finding stimulated us to investigate the gas-phase fragmentation reactions and the key diagnostic ions of the drug degradation products and to carry out the complete structural characterization of this new entity by nuclear magnetic resonance (NMR) analysis. We also described for the first time an unknown impurity of this drug, and assessed its genotoxic potential through in silico methods. These data may contribute to the still scarce information publicly available regarding degradation products in pharmaceuticals.

\section{Experimental}

\section{Samples}

Betahistine dihydrochloride was obtained from LEBSA (Espinos Y Bofill S. A. laboratories). Impurities $\mathbf{3}$ and $\mathbf{4}$ were acquired from Sigma-Aldrich. Impurity C1 (6) was obtained by preparative chromatography purification. Mobile phases constituted of (A) aqueous formic acid $(0.1 \%)$ solution and (B) methanol $(0.1 \%$ formic acid). Pumps programming: 5 to $13.3 \%$ of A in 10 min. Peaks with retention time $\left(t_{R}\right)$ of 7.8 min was collected. Compound $\mathbf{5}$ was synthesized by following a known procedure: ${ }^{31}$ compound 1 (0.05 g, $3.7 \mathrm{mmol})$, toluene $(2.5 \mathrm{~mL})$, and 4-vinylpiridine $(\mathbf{3})$ were placed inside a $10-\mathrm{mL}$ roundbottom flask. Ammonium chloride (10 mg, $0.19 \mathrm{mmol}$ ) was added, and the mixture was stirred in an oil bath at $85-86^{\circ} \mathrm{C}$ for $60 \mathrm{~h}$. The mixture was then purified by flash chromatography; methylene chloride/methanol (6:1) was used as eluent. Yield: $65 \%$ of colorless oil.

\section{Mass spectrometry analysis}

Stock solutions of the betahistine impurities C (5) and $\mathrm{C} 1$ (6) were prepared for MS analysis from a $0.05 \mathrm{mg} \mathrm{mL}^{-1}$ solution of each compound in methanol/water $(5: 5 \mathrm{v} / \mathrm{v})$. The impurities were analyzed by direct infusion into three different mass spectrometry: (i) AmaZon SL (Bruker Daltonics) equipped with an ESI source and an ion trap analyzer; (ii) micrOTOF Q II (Bruker Daltonics) equipped with an ESI source and a time of flight (TOF) analyzer; and (iii) Applied Biosystem/Sciex API 3200 (AB Sciex) equipped with an ESI source and a triple quadrupole analyzer. The analyses were accomplished in the positive ion mode; nitrogen at a pressure of $50 \mathrm{psi}$ and flow of $7 \mathrm{~L} \mathrm{~min}^{-1}$ (dry gas) was employed as nebulizer gas. The capillary voltage and the temperature were set at $3500 \mathrm{~V}$ and $220^{\circ} \mathrm{C}$, respectively, and helium was used as collision gas. 


\section{NMR characterization}

The NMR spectra were recorded on a Bruker spectrometer AVANCE 400 operating at 400 and $100 \mathrm{MHz}$ for hydrogen nuclei and ${ }^{13} \mathrm{C}$ nuclei, respectively. Assignments were based on distortionless enhancement by polarization transfer (DEPT)-135, correlation spectroscopy (COSY), and heteronuclear multiple bond (HMBC) and heteronuclear single quantum (HSQC) correlation maps.

$N$-Methyl-2-(pyridin-2-yl)- N-(2-(pyridin-2-yl)ethyl) ethanamine (5)

${ }^{1} \mathrm{H}$ NMR (400 MHz, $\left.\mathrm{CDCl}_{3}\right) \delta 8.50(\mathrm{dd}, J 4.6$ and $1.8 \mathrm{~Hz}, 2 \mathrm{H}), 7.57$ (td, $J 7.8$ and $1.8 \mathrm{~Hz}, 2 \mathrm{H}), 7.16$ (dd, $J 7.8$ and $1.0 \mathrm{~Hz}, 2 \mathrm{H}), 7.11$ (ddd, $J 7.8,4.6,1.0 \mathrm{~Hz}$, 2H), 3.03-2.99 (m, 4H), 2.95-2.92 (m, 4H), 2.44 (s, 3H); ${ }^{13} \mathrm{C} \mathrm{NMR}\left(100 \mathrm{MHz}, \mathrm{CDCl}_{3}\right) \delta 160.1,149.1,136.4,123.3$, 121.2, 57.1, 41.8, 35.5.

2-(2-(Methylamino)ethyl)-1-(2-(pyridin-2-yl)ethyl)pyridin1-ium chloride (6)

${ }^{1} \mathrm{H}$ NMR (400 MHz, D $\left.2 \mathrm{O}\right) \delta 8.80(\mathrm{~d}, J 5.5 \mathrm{~Hz}, 1 \mathrm{H})$, $8.74(\mathrm{~d}, J 5.7 \mathrm{~Hz}, 1 \mathrm{H}), 8.58(\mathrm{~m}, 1 \mathrm{H}), 8.53(\mathrm{~m}, 1 \mathrm{H}), 8.08$ $(\mathrm{d}, J 8.1 \mathrm{~Hz}, 1 \mathrm{H}), 7.97-8.00(\mathrm{~m}, 3 \mathrm{H}), 5.13(\mathrm{t}, J 7.9 \mathrm{~Hz}$, 2H), 3.80 (t, J 7.9 Hz, 1H), 3.68-3.73 (m, 2H), 3.60-3.64 $(\mathrm{m}, 2 \mathrm{H}), 2.85(\mathrm{~s}, 3 \mathrm{H}) ;{ }^{13} \mathrm{C}$ NMR $\left(100 \mathrm{MHz}, \mathrm{D}_{2} \mathrm{O}\right) \delta 152.8$, 150.3 , 147.2, 147.0, 146.3, 142.7, 129.5, 127.7, 127.5, $126.3,55.8,46.1,33.6,33.3,28.6$.

LC analysis

The liquid chromatography analyses were performed on (i) Shimadzu Nexera X2 liquid chromatograph equipped with LC-30AD pumps, auto-sampler, SIL-20AT PDA detector operated at $260 \mathrm{~nm}, \mathrm{CTO}-20 \mathrm{~A}$ oven at $40{ }^{\circ} \mathrm{C}$, and Shim-pack (Shimadzu) XR-ODS III column measuring $1.6 \times 75 \times 2.0 \mathrm{~mm}$. Mobile phase $(\mathrm{A})$ water/HFBA (heptafluorobutyric acid) (10 mM), (B) acetonitrile/HFBA $(10 \mathrm{mM})$; mobile phase flow: $0.5 \mathrm{~mL} \mathrm{~min}^{-1}$ and (ii) Waters Acquity UPLCCSHC18 column $(50 \times 2.1 \mathrm{~mm}, 1.7 \mu \mathrm{m}$ particle diameter) was used for analytes separation. The molecules were eluted with a gradient of heptafluorobutyric acid $10 \mathrm{mM}$ (solution A) and acetonitrile (solution B) at a temperature of $40{ }^{\circ} \mathrm{C}$ and flow rate of $0.5 \mathrm{~mL} \mathrm{~min}{ }^{-1}$. The gradient setting is shown in Table 1 . The injection volume was $1 \mu \mathrm{L}$.

\section{Forced degradation experiments}

\section{Acid and alkali hydrolysis}

The hydrolysis experiments were performed by submitting the samples of raw material and tablets to hydrochloride acid $6 \mathrm{M}$ at $60{ }^{\circ} \mathrm{C}$ for 10 days or sodium hydroxide $2 \mathrm{M}$. The samples were diluted 1:1 with the diluent solution and filtered through $0.22 \mu \mathrm{m}$ polyvinylidene difluoride (PVDF) filters. Blank acid and alkali controls were also injected.

\section{Oxidative and metallic ions degradations}

Hydrogen peroxide $30 \%$ was used to force oxidative degradation during 10 days under room temperature, while copper chloride $50 \mathrm{mM}$ for one day at room temperature was the condition chosen for metallic ions stress. Again, the working solutions consisted of the primary solutions diluted once in a standard diluent, and blank solutions were prepared using hydrogen peroxide or copper chloride solely.

\section{Photolytic degradation}

The photo exposition was performed in a photo stability chamber. Photolytic conditions were $2.4 \mathrm{klux} \mathrm{h}^{-1}$ and $400 \mathrm{Wh} \mathrm{m}^{-2}$. Once the photo exposition cycle was completed, samples were diluted and filtered through $0.22 \mu \mathrm{m}$ PVDF filters to a vial before injection. Control experiments of photodegradation were carried out by covering the samples with aluminium foil.

\section{Heat degradation}

The same procedure employed for photolytic degradation was carried out for heat degradation, using a hot air oven during 10 days at $60{ }^{\circ} \mathrm{C}$. Aliquots of $10 \mathrm{mg}$ of betahistine or $150 \mathrm{mg}$ of placebo were taken and dissolved in $10 \mathrm{~mL}$ of diluent to get the final solutions to be analyzed.

\section{Effect of humidity}

A desiccator containing sodium chloride $0.4 \mathrm{~g} \mathrm{~L}^{-1}$ to produce an ambient with $75 \%$ of humidity was used for this assay. Humidity was controlled by a thermohydrometer to be maintained stable. Aliquots of $10 \mathrm{mg}$ of betahistine or $150 \mathrm{mg}$ of placebo were left inside the desiccator during 10 days. Then, $10 \mathrm{~mL}$ of diluent was added to each sample and mixed until complete dissolution. The samples were filtered to a vial before ultra-performance liquid chromatography (UPLC) analysis.

\section{Accelerated and long-term stability study}

Stability studies were conducted by exposing the final product in its primary package to $40{ }^{\circ} \mathrm{C}, 75 \%$ relative humidity during 6 months for accelerated condition and to $30{ }^{\circ} \mathrm{C}, 75 \%$ humidity zone IVB during 24 months. 


\section{In silico mutagenicity prediction}

The ICH M7 guideline ${ }^{32}$ recommends the use of two different quantitative structure-activity relationship (QSAR) methodologies to predict mutagenicity of drug impurities. One should be expert rule-based, and the other one should be statistical-based. Here, we used Derek Nexus ${ }^{33}$ and Sarah Nexus, ${ }^{33}$ which meet that $\mathrm{ICH}$ recommendation. The predictions were carried out by using a specific tool for ICH M7 mutagenicity assessment, following the standard setup as described in the Supplementary Information.

\section{Results and Discussion}

\section{Forced degradation studies}

Seven different stress conditions were used to force degradation of betahistine raw material (active pharmaceutical ingredient (API)), tablets and placebo. The percentage of degradation was calculated based on the comparison of the degraded sample with a non-degraded sample as reference (Table 1). Overall, the raw material and the final product showed the same profile of chemical stability, as both were majorly susceptible to alkaline and oxidative degradation. Under the alkaline condition, the tablets were still more labile than raw material, which may be a consequence of the marked placebo instability to the higher $\mathrm{pH}$ medium (Figure $2 \mathrm{c}$, red trace).

Table 1. Levels of betahistine in the raw material and the tablets after exposure to each stress condition

\begin{tabular}{|c|c|c|c|}
\hline \multicolumn{2}{|c|}{ Stress condition } & \multirow{2}{*}{$\begin{array}{c}\text { Sample } \\
\text { raw material }\end{array}$} & \multirow{2}{*}{$\begin{array}{c}\text { Betahistine } \\
1 \% \\
93.51\end{array}$} \\
\hline Alkaline & $\begin{array}{c}2 \mathrm{M} \mathrm{NaOH}, 10 \text { days, } \\
60^{\circ} \mathrm{C}\end{array}$ & & \\
\hline Alkaline & $\begin{array}{c}2 \mathrm{M} \mathrm{NaOH}, 10 \text { days, } \\
25^{\circ} \mathrm{C}\end{array}$ & tablets & 84.37 \\
\hline \multirow{2}{*}{ Acidic } & \multirow{2}{*}{$\begin{array}{c}6 \mathrm{M} \mathrm{HCl}, 10 \text { days, } \\
60^{\circ} \mathrm{C}\end{array}$} & raw material & 98.50 \\
\hline & & tablets & 96.34 \\
\hline \multirow{2}{*}{ Oxidative } & \multirow{2}{*}{$\begin{array}{c}\mathrm{H}_{2} \mathrm{O}_{2} 10 \%, 10 \text { days, } \\
25{ }^{\circ} \mathrm{C}\end{array}$} & raw material & 99.01 \\
\hline & & tablets & 84.84 \\
\hline \multirow{2}{*}{ Metallic ions } & \multirow{2}{*}{$\begin{array}{c}50 \mathrm{mM} \mathrm{CuCl}_{2}, 24 \mathrm{~h}, \\
25^{\circ} \mathrm{C}\end{array}$} & raw material & 100.57 \\
\hline & & tablets & 97.83 \\
\hline \multirow{2}{*}{ Photo chemical } & \multirow{2}{*}{$\begin{array}{l}2.4 \mathrm{klux} \mathrm{h}^{-1} \text { and } \\
400 \mathrm{Wh} \mathrm{m}^{-2}\end{array}$} & raw material & 99.69 \\
\hline & & tablets & 98.08 \\
\hline \multirow{2}{*}{ Thermal } & \multirow{2}{*}{10 days, $60^{\circ} \mathrm{C}$} & raw material & 96.96 \\
\hline & & tablets & 91.85 \\
\hline \multirow{2}{*}{ Humidity } & \multirow{2}{*}{10 days, $75 \%$ humidity } & raw material & 99.89 \\
\hline & & tablets & 101.05 \\
\hline
\end{tabular}

Forced degradation of betahistine as API and tablets has been previously studied. Similarly to what we reported here, the authors found that betahistine is very sensitive to oxidation. A decrease of about $15 \%$ of betahistine occurred after exposure to hydrogen peroxide $20 \%$ for $30 \mathrm{~min},{ }^{27}$ while we observed a similar decrease using a less concentrated solution of hydrogen peroxide and a longer exposure.

Notwithstanding, they observed a susceptibility to UV light which was not seen in our study, while no degradation under alkaline condition was reported by them. The different outcomes after exposure to photochemical may be related to differences in the exposure setups. Although the authors had not specified the exact intensity of light to which the samples were exposed, they have mentioned a distance of $5 \mathrm{~cm}$ from the UV source, which can result in a more intense exposure compared to our photo stability chamber where this distance is around $30 \mathrm{~cm}$. Regarding the alkaline hydrolysis, we observed a decay of $15 \%$ of betahistine in the tablets after exposure to $2 \mathrm{M} \mathrm{NaOH}$ for 10 days at room temperature, which is a very different condition than that performed by Khedr and Sheha: ${ }^{27}$ $1 \mathrm{M} \mathrm{NaOH}, 100{ }^{\circ} \mathrm{C}, 5 \mathrm{~min}$. Additionally, such different profile can be also attributed to the marked instability of the placebo, as we discussed above.

Considering the maximum daily dose of betahistine being $48 \mathrm{mg}$, the thresholds of reporting, identification, and qualification of impurities are $0.1,0.2$, and $0.42 \%$, respectively. At the end of the long-term stability study $\left(30^{\circ} \mathrm{C}\right.$, $75 \%$ relative humidity) in betahistine tablets, the impurity $\mathrm{C}$ and an unknown impurity with relative retention time (RTT) of $1.74 \mathrm{~min}$ (from now on called impurity $\mathrm{C} 1$ ) were found in levels higher than those stated in the $\mathrm{ICH}$ Q3B ${ }^{24}$ for identification and qualification, 3.26 and $0.77 \%$, respectively. Nonetheless, no significant decay of betahistine was detected. Although the raw material and the final product have shown higher susceptibility to alkaline and oxidative stress, the major impurities observed in the long-term stability study were not formed under these conditions. Based on the stress experiments, we can infer that both impurities result from degradation of betahistine under heating conditions, once an expressive increase of impurity $\mathrm{C} 1$ and impurity $\mathrm{C}$ (5) was noticed only after exposure at $60{ }^{\circ} \mathrm{C}$ during 10 days, but not in other cases. The samples collected at the end of the long-term stability study, containing the impurities in increased levels, were used for identification assessment. A summary of all impurities found in the degradation studies is shown in the Supplementary Information.

\section{Characterization of impurity $\mathrm{C} 1$}

Interestingly, the high-resolution mass spectrometry 


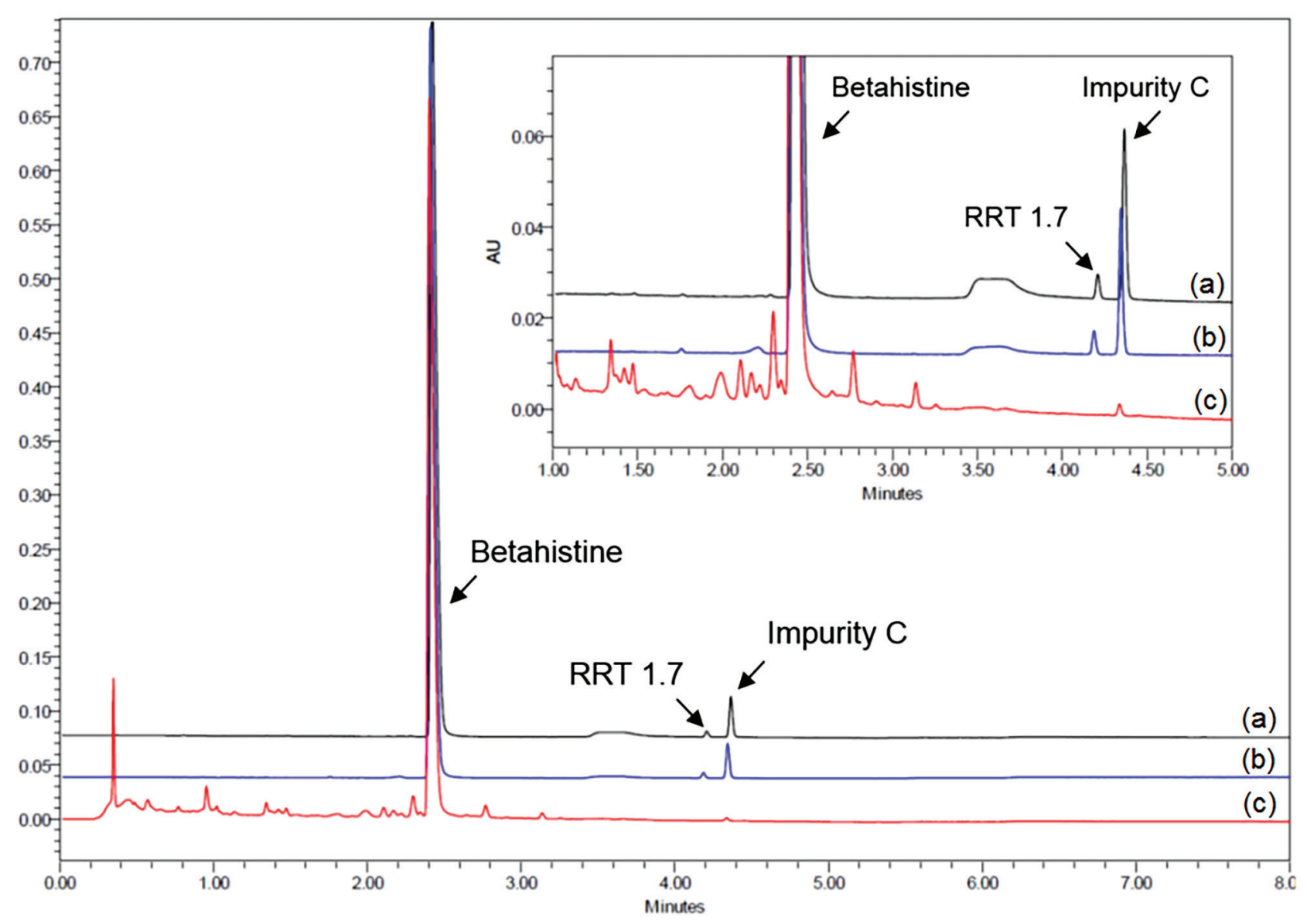

Figure 2. Chromatograms obtained for stress of drug product: (a) long-term stability study (black); (b) thermic (blue) and (c) alkaline stress (red).

(ESI-TOF) analysis of betahistine impurities $\mathrm{C}$ and $\mathrm{C} 1$ afforded isomeric ions $(\mathrm{m} / \mathrm{z} 242)$. Therefore, we conducted systematic MS/MS and $\mathrm{MS}^{\mathrm{n}}$ analyses to propose the structure of the new molecule (Figure 3).

The known impurity C (5) MS/MS analysis revealed two major fragment ions: $\mathrm{m} / \mathrm{z} 149$ and 106 . The ion trap spectra confirmed the formation of $\mathrm{m} / \mathrm{z} 106$ from the ion $\mathrm{m} / z, 149$. This information fully agreed with the proposed structure. Initial protonation may have occurred at the three most basic positions. Protonation at the tertiary amine directly afforded the primary carbocation ion at $\mathrm{m} / \mathrm{z} 106$. On the other hand, protonation at the pyridinyl nitrogen opened the possibility for neutral elimination assisted by the tertiary amine electrons, to yield an ammonium ion at $m / z$ 149. Sequential neutral amine elimination produced an initial primary carbocation (with low stability), but fast rearrangement gave the ion at $m / z, 106$, stabilized by three resonance forms.

Notably, detailed mass spectrometry analysis of impurity $\mathrm{C} 1$ showed two new fragment ions, but no ion at $\mathrm{m} / \mathrm{z}$ 149. Again, $\mathrm{m} / \mathrm{z} 106$ may have originated directly from the precursor ion. Figure 4 contains a possible molecular ion related to the betahistine impurity $\mathrm{C} 1$, which has not been reported yet. The ions at $m / z 199$ and 211 also support the proposal. Initial classic terminal amine elimination afforded the ion at $m / z 211$, and a long-distance anchimeric assistance induced elimination reaction between the terminal amine and one more $\mathrm{CH}_{2}$.

In the degradation process, impurity $\mathrm{C} 1$ appeared to result from betahistine pyridine nitrogen attack onto the 2-vinylpyridine (3) generated in situ. Nonetheless, some attempts to synthesize $\mathrm{C} 1$ by reacting betahistine (1) with 2-vinylpyridine (3) failed under several classic conditions ${ }^{34}$ and always gave compound $\mathbf{5}$ as the major product. Moreover, different reactional times, additives (such as Lewis acids), and even nitrogen-protecting strategies (i.e., aliphatic betahistine nitrogen protection with tert-butyloxycarbonyl $(\mathrm{BOC})^{35}$ and 9-fluorenylmethyloxycarbonyl (FMOC) ${ }^{36}$ groups) did not afford the desired product. Although in the forced betahistine degradation study we have obtained a great quantity of impurity $\mathrm{C}(\mathbf{5})$, the solid phase environment of the tablet seemed to play an important role in the formation and mainly in the stabilization of the pyridinium salt.

To complete the structural characterization of the impurity $\mathrm{C} 1$ (compound 6), we also resorted to NMR 


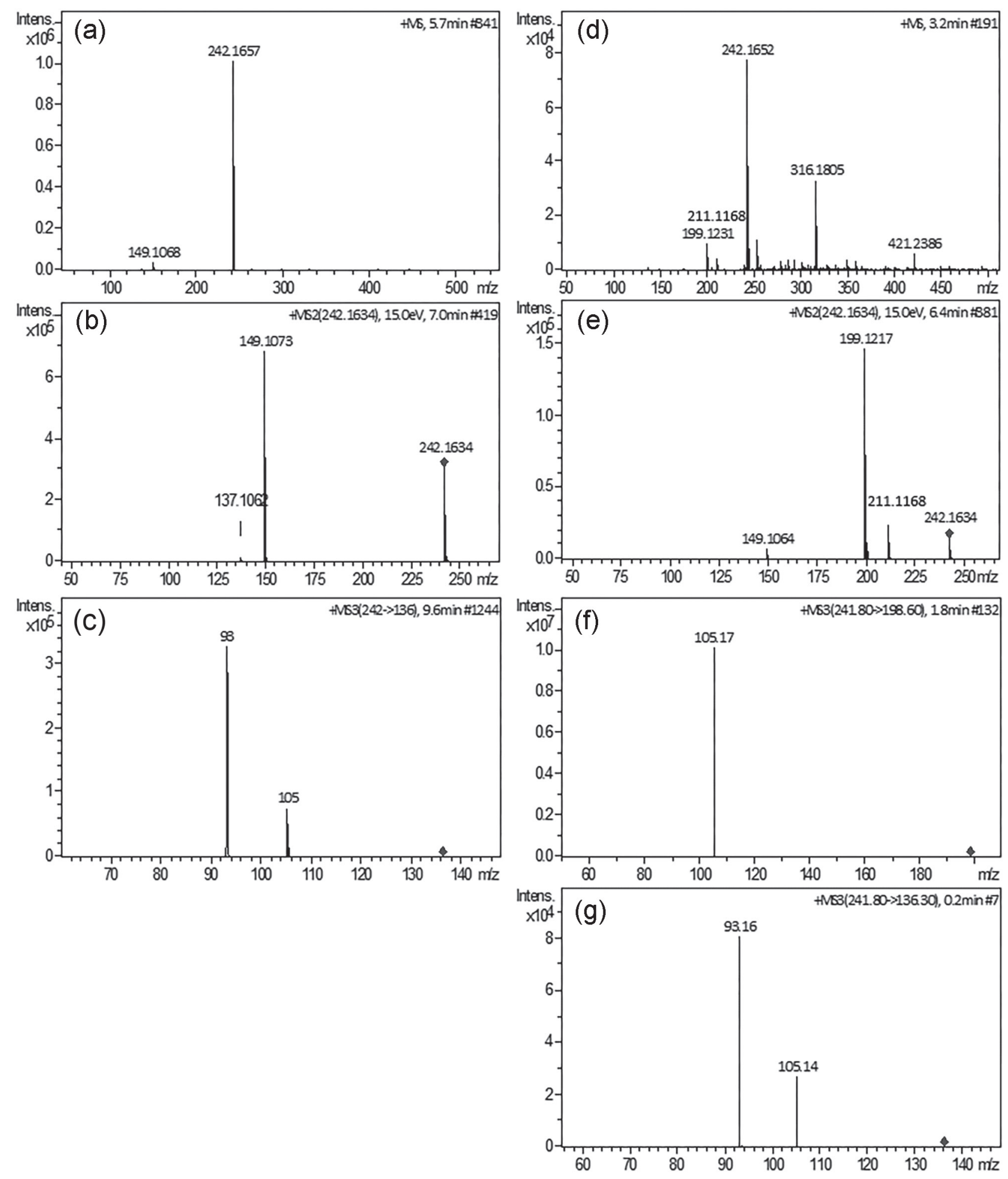

Figure 3. Directed injection ESI-ion trap mass spectra of 5 in: (a) TIC, (b) MS/MS of $m / z$ 242, and (c) MS ${ }^{3}$ of $m / z$, 136; and of 6 in: (d) TIC, (e) MS/MS of $m / z 242$, (f) $\mathrm{MS}^{3}$ of $m / z, 198$, and (g) $\mathrm{MS}^{3}$ of $m / z, 136 \mathrm{Da}$.

spectroscopy data. As a matter of comparison, we also registered the impurity $\mathrm{C}$ (5) NMR spectral data (Table 2). The ${ }^{1} \mathrm{H}$ NMR spectrum of $\mathbf{5}$ displayed signals of seven spin systems: four emerged in the aromatic field (from 9.00 to $7.00 \mathrm{ppm}$ ), whereas three arose in the aliphatic field (from 4.00 to $2.50 \mathrm{ppm}$ ). On the other hand, the impurity $\mathrm{C} 1$ (6) exhibited ten spin systems, so it was less symmetric than 5: five in the aromatic field (same window) and four in the aliphatic field. The most significant difference between the NMR spectra of $\mathbf{5}$ and $\mathbf{6}$ was the 


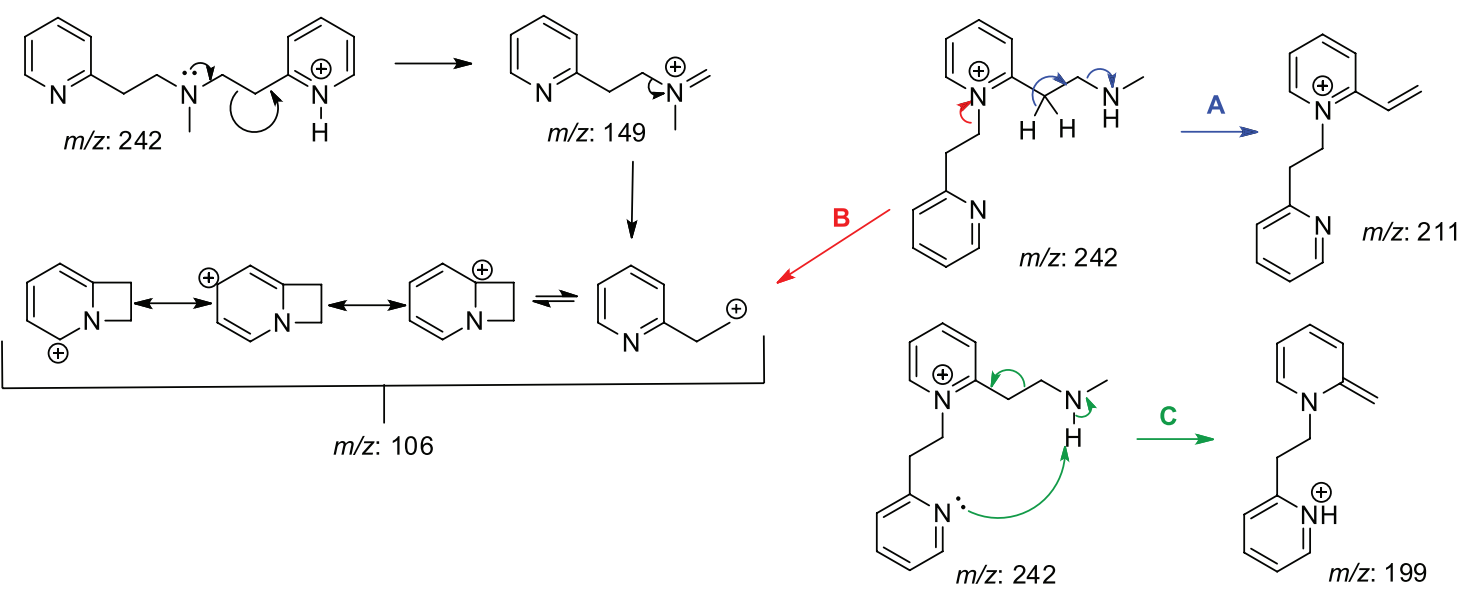

Figure 4. Proposed mechanism for the formation of the major ions of impurities C (5) and C1.

triplet in $5.13 \mathrm{ppm}(J 7.9 \mathrm{~Hz})$ in the NMR spectrum of 6 (Table 2, entry 9), which was attributed to the methylenepyridinium salt (Figure 5). A comparative analysis of the ${ }^{13} \mathrm{C}$ NMR spectra of compounds 5 and $\mathbf{6}$ showed that the symmetric compound $\mathbf{5}$ had half the number of carbons as compared to $\mathbf{6}$.

Table 2. Assignment of the ${ }^{1} \mathrm{H}$ and ${ }^{13} \mathrm{C}$ NMR signals of impurities 5 and $\mathbf{6}$<smiles>CN(CCc1ccccn1)Cc1ccccn1</smiles><smiles></smiles>

\begin{tabular}{|c|c|c|c|c|}
\hline \multirow{2}{*}{ Atom } & \multicolumn{2}{|c|}{$\delta_{\mathrm{H}} ;$ multiplicity; $J / \mathrm{Hz}$} & \multicolumn{2}{|c|}{$\delta_{\mathrm{C}}$} \\
\hline & 5 & 6 & 5 & 6 \\
\hline 1 & $8.50 ; \mathrm{dd} ; J 4.6,1.8$ & $8.80 ; \mathrm{d} ; J 5.5$ & 149.1 & 146.3 \\
\hline 2 & $7.11 ;$ ddd; $J 7.8,4.6,1.0$ & 8.00-7.97; m & 121.2 & 127.5 \\
\hline 3 & $7.57 ; \mathrm{td} ; J 7.8,1,8$ & $8.58 ; \mathrm{m}$ & 136.4 & 147.2 \\
\hline 4 & $7.16 ; \mathrm{dd} ; J 7.8,1.0$ & $8.08 ; \mathrm{d} ; J 8.1$ & 123.3 & 129.5 \\
\hline 5 & - & - & 160.1 & 152.8 \\
\hline 6 & 2.95-2.92; m & $3.72-3.68 ; \mathrm{m}$ & 35.5 & 28.6 \\
\hline 7 & $3.03-2.99 ; \mathrm{m}$ & $3.64-3.60 ; \mathrm{m}$ & 57.1 & 46.1 \\
\hline 8 & $2.44 ; \mathrm{s}$ & $2.85 ; \mathrm{s}$ & 41.9 & 33.3 \\
\hline 9 & 3.03-2.99; m & $5.13 ; \mathrm{t} ; J 7.9$ & 57.1 & 55.8 \\
\hline 10 & 2.95-2.92; m & $3.80 ; \mathrm{t} ; J 7.9$ & 35.5 & 33.6 \\
\hline 11 & - & - & 160.1 & 150.3 \\
\hline 12 & $7.16 ; \mathrm{dd} ; J 7.8,1.0$ & 8.00-7.97; m & 123.3 & 127.7 \\
\hline 13 & $7.57 ; \mathrm{td} ; J 7.8,1.8$ & $8.53 ; \mathrm{m}$ & 136.4 & 147.0 \\
\hline 14 & 7.11; ddd; $J 7.8,4.6,1.0$ & 8.00-7.97; m & 121.2 & 126.3 \\
\hline 15 & $8.50 ; \mathrm{dd} ; J 4.6,1.8$ & $8.74 ; \mathrm{d} ; J 5.7$ & 149.1 & 142.7 \\
\hline
\end{tabular}

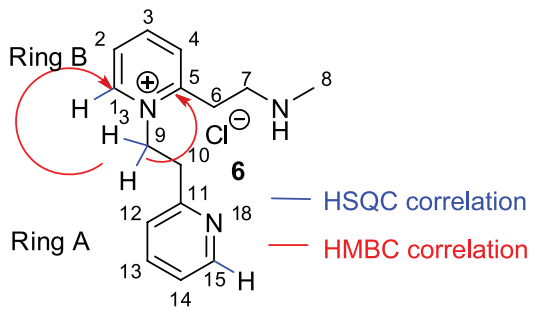

Figure 5. Major HMBC and HSQC correlations for compound 6.

Analyses of the HSQC correlation maps of $\mathbf{6}$ corroborated the proposed structure. $\mathrm{H}-15$ emerged as a doublet $(8.74 \mathrm{ppm}, \mathrm{d}, J 5.7 \mathrm{~Hz})$ that correlated with carbon at $142.7 \mathrm{ppm}$, in a pyridyl moiety ring A. H-1 arose as a doublet $(8.80 \mathrm{ppm}, J 5.5 \mathrm{~Hz}$ ) that correlated with carbon at $146.3 \mathrm{ppm}$ and was attributed to pyridinium salt (ring B). $\mathrm{H}-4$ appeared as a doublet $(8.08 \mathrm{ppm}, J 8.1 \mathrm{~Hz})$ that correlated with a carbon at $129.5 \mathrm{ppm}$ (ring B).

The methylene group named H-10 (3.80 ppm, t, $J 7.9 \mathrm{~Hz}$ ) correlated with a carbon in $33.6 \mathrm{ppm}$, which also correlated with H-9 (5.13 ppm, t, J 7.9 Hz). The lower field signal in $5.13 \mathrm{ppm}$ correlated with a carbon in $55.8 \mathrm{ppm}$ and was ascribed to the $\mathrm{N}$-bonded alkyl substituent of pyridyl ring $\mathrm{B}$, which was decisive for the structural elucidation of 6 .

As for the HMBC correlation map, hydrogen in 5.13 ppm correlated with a carbon at $146.3 \mathrm{ppm}$ in ring B. Moreover, the alkyl group attached to the quaternary carbon at $152.8 \mathrm{ppm}$ (ring B) displayed methylene hydrogens H-12 and $\mathrm{H}-13$ at 3.68-3.72 and 3.60-3.64 ppm, which emerged as multiplets. Figure 5 depicts the major HMBC and HSQC correlations for compound 6.

\section{In silico mutagenic studies}

Once the chemical structure of the impurity $\mathrm{C} 1(\mathbf{6})$ was identified by mass spectrometry, we started the 
toxicological assessment by the in silico predictions of mutagenicity. Both API and impurities were classified as inactive in Derek Nexus, ${ }^{33}$ the expert rule-based system, without misclassified or unclassified features. A similar result was obtained in Sarah Nexus, ${ }^{33}$ the statistical-based system, where the API, impurity C (5) and impurity C1 (6) were classified as negative for mutagenicity with 62,39 , and $50 \%$ of confidence, respectively. The confidence level in Sarah Nexus is not a measure of the probability of the query compound being mutagenic, but it is related to the accuracy of the prediction, which is calculated based on the certainty and reliability of the model and the data ${ }^{37}$ Low confidences can occur when hypotheses leading to the prediction have low confidences individually, meaning that a certain chemical feature leading the hypothesis is not strongly associated with neither positive nor negative results. This can also be due to the most similar compounds brought up by the hypothesis giving inconsistent results (mixed positive and negative results), the low similarity between the query compound and the compounds in the training set, or both. ${ }^{38}$ Because the confidence level is not a measure of probability, a result of $50 \%$ of confidence does not mean an equivocal prediction. Actually, a negative result with $50 \%$ confidence has correlated to a negative predictivity value (NPV) of $90 \% .{ }^{39}$ This was established based on an internal validation study carried out using a dataset of 7677 compounds. So, although the levels of confidence obtained for the betahistine and the impurities tested here might seem low, they represent accurate predictions of no mutagenicity for those compounds.

In silico tools can be especially useful for those cases where is not possible to test the target compound due to the limitation of obtaining the amount required for experimental assays, for instance when the compound has a short halflife. Particularly in the field of degradation products this is a frequent obstacle. Assuming we had to perform an Ames test (in the range of 500-5000 $\mu$ g per plate) with the sample of betahistine tablets containing the impurities, for example, and taking into account the proportion of betahistine to excipients in the tablets $(6.4 \%)$ and the percentages of impurity $\mathrm{C} 1(\mathbf{6})$ and impurity $\mathrm{C} \mathrm{(5)}$ in the final product ( 0.77 and $3.26 \%$, respectively), the impurities would be tested in the ranges of 0.00246-2.46 $\mu \mathrm{g}$ per plate for impurity $\mathrm{C} 1$ (6), and 0.01043-10.43 $\mu \mathrm{g}$ per plate for impurity $\mathrm{C}(\mathbf{5})$. According to a data survey of chemicals knowingly mutagenic in bacteria, a concentration of at least $250 \mu \mathrm{g}$ per plate is suitable to detect a mutagenic effect in a typical bacterial reverse mutation assay. ${ }^{40}$ Generally, levels below these cannot be appropriate to evaluate the mutagenicity of chemicals properly, which is the case in the present study.
Finally, there are several studies in the literature regarding impurities profiling from the analytical point of view, but few of them addresses the related toxicological issues. ${ }^{41-44}$ Approaches similar to that we have applied here have been used to the qualification of impurities from different drug products. ${ }^{45-47}$ Particularly for betahistine, although there is the report of stress degradation studies and development of stability-indicating assay method, ${ }^{27}$ no data regarding qualification of degradation products is available so far. On the other hand, given the clinical relevance of betahistine and the duration of treatment, ${ }^{48,49}$ the estimate of mutagenicity of its impurities may be relevant to understand potential risks to the health posed by the treatment with this drug product.

\section{Conclusions}

Systematic investigation of a forced degradation betahistine sample led to the detection and structural characterization of a new entity, which was named betahistine impurity $\mathrm{C} 1$. Studies on the dissociation reactions undergone by impurity $\mathrm{C}(\mathbf{5})$ and new impurity $\mathrm{C} 1$ (6) confirmed the presence of two isomeric ions in the LC-MS analysis. Structural elucidation of the major fragment ions was successfully performed and can be used to confirm the presence of the correct structures in any accelerated or forced drug studies. By using two different and complementary computational tools, we showed that there are no structural alerts indicative of mutagenicity, allowing us to classify both impurities as non-mutagenic. This may be useful in the risk assessment of betahistine drug products containing those impurities, as well as to support future investigations of betahistine degradation products, as this is not mandatory for marketed drugs in light of the current ICH guidelines.

\section{Supplementary Information}

Supplementary information is available free of charge at http://jbcs.sbq.org.br as PDF file.

\section{Acknowledgments}

The authors thank: São Paulo Research Foundation (FAPESP, Proc. 2015/12811-9, Proc. 2014/50265-3, Proc. 2018/14150-8), CNPq, and CAPES for financial support; Analytical Development and Radical Innovation Unit, from Aché Laboratories, for the support in the experiments and technical discussions; Richard Williams and Alex Cayley, from Lhasa Limited, UK, for reviewing the manuscript, especially in the in silico studies; and Prof Dr Norberto P. Lopes for reviewing the mass spectroscopy data. 


\section{References}

1. Frew, I. J. C.; Menon, G. N.; Postgrad. Med. J. 1976, 52, 501.

2. Wilmot, T. J.; Menon, G. N.; J. Laryngol. Otol. 1976, 90, 833.

3. Arrang, J. M.; Garbarg, M.; Quach, T. T.; Tuong, M. D. T.; Yeramian E.; Schwartz, J. C.; Eur. J. Pharmacol. 1985, 111, 73.

4. Oosterveld, W. J.; J. Laryngol. Otol. 1984, 98, 37.

5. Suga, F.; Snow, J. B.; Laryngoscope 1969, 79, 1956.

6. Martinez, D. M.; Acta Oto-Laryngol., Suppl. 1972, 305, 29.

7. Anderson, W. D.; Kubicek, W.; Am. J. Anat. 1971, 132, 179.

8. Dziadziola, J. K.; Laurikainen, E. L.; Rachel, J. D.; Quirk, W. S.; Otolaryngol.--Head Neck Surg. 1999, 120, 400.

9. Mira, E.; Guidetti, G.; Ghilardi, P. L.; Fattori, B.; Malannino, N.; Maiolino, L.; Mora, R.; Ottoboni, S.; Pagnini, P.; Leprini, M.; Pallestrini, E.; Passali, D.; Nuti, D.; Russolo, M.; Tirelli, G.; Simoncelli, C.; Brizi, S.; Vicini, C.; Frasconi, P.; Eur. Arch. Oto-Rhino-Laryngol. 2003, 260, 73.

10. Soto, E.; Chavez, H.; Valli, P.; Benvenuti, C.; Vega, R.; Acta Oto-Laryngol., Suppl. 2001, 545, 19.

11. Unemoto, H.; Sasa, M.; Takaori, S.; Ito, J.; Matsuoka, I.; Arch. Oto-Rhino-Laryngol. 1982, 236, 229.

12. Elia, J. C.; JAMA, J. Am. Med. Assoc. 1966, 196, 187.

13. Agência Nacional de Vigilância Sanitária (ANVISA); Guia para a Realização de Estudos de Estabilidade; Resolução-RE No. 1, de 29 de julho de 2005, DOU No. 146, de 1 de agosto de 2005, Brasília, Brazil. Available at http://portal.anvisa.gov. br/documents/10181/2718376/RE_01_+2005_.pdf/18746b14c3a6-4e43-9721-694c2488f274?version=1.0, accessed in February 2019; Melo, S. R. O.; Homen-de-Mello, M.; Silveira, D.; Simeoni, L. A.; PDA J. Pharm. Sci. Technol. 2014, 68, 221.

14. Karim, S.; Baie, S. H.; Hay, Y. K.; Latif, A.; Shamim, R.; Hussain, K.; Bukhari, N. I.; Lat. Am. J. Pharm. 2013, 32, 431.

15. Singh, S.; Junwal, M.; Modhe, G.; Tiwari, H.; Kurmi, M.; Parashar, N.; Sidduri P.; TrAC, Trends Anal. Chem. 2013, 49, 71.

16. Jain, D.; Basniwal, P. K.; J. Pharm. Biomed. Anal. 2013, 86, 11.

17. Blessy, M.; Patel, R. D.; Prajapati, P. N.; Agrawal, Y. K.; J. Pharm. Anal. 2014, 4, 159.

18. Ahuja, S. In Separation Science and Technology, vol. 5; Ahuja, S.; Alsante, K. M., eds.; Academic Press: London, 2004, p. 1.

19. Satinder, A.; Alsante, K. M.; Handbook of Isolation and Characterization of Impurities in Pharmaceuticals, $1^{\text {st }}$ ed.; Academic Press: London, 2004.

20. Basak, A. K.; Raw, A. S.; Yu, L. X.; Adv. Drug Delivery Rev. 2007, 5, 91 .

21. Maggio, R. M.; Calvo, N. L.; Vignaduzzo, S. E.; Kaufman, T. S.; J. Pharm. Biomed. Anal. 2014, 101, 102.

22. Sautel, M.; Krstulovic, A. M.; J. Sep. Sci. 2005, 13, 1529.

23. International Conference on Harmonisation of Technical Requirements for Registration of Pharmaceuticals for Human Use (ICH); Impurities in New Drug Substances Q3A (R2);
ICH: London, 2006. Available at https://www.ich.org/products/ guidelines/quality/quality-single/article/impurities-in-newdrug-substances.html, accessed in February 2019.

24. International Conference on Harmonisation of Technical Requirements for Registration of Pharmaceuticals for Human Use (ICH); Impurities in New Drug Products Q3B (R2); ICH: London, 2006. Available at https://www.ich.org/products/ guidelines/quality/quality-single/article/impurities-in-newdrug-substances.html, accessed in February 2019.

25. International Conference on Harmonization of Technical Requirements for Registration of Pharmaceuticals for Human Use (ICH); Impurities: Guideline for Residual Solvents Q3C (R6); ICH: London, 2016. Available at https://www.ich.org/ products/guidelines/quality/quality-single/article/impuritiesin-new-drug-substances.html, accessed in February 2019.

26. The United States Pharmacopoeia (USP), USP 37-NF 32, vol. 2, The United States Pharmacopeial Convention, Rockville, 2013, p. 1954-1955; British Pharmacopoeia 2019, vol. 1, The Stationery Office, London, 2019, p. I-292-I-293.

27. Khedr, A.; Sheha, M.; J. Chromatogr. B 2008, 869, 111.

28. Chequer, D.; Lizier, F. M.; de Felicio, T. M.; Zanoni, R.; Debonsi, M. V. B.; Maria, H.; Lopes, N. P.; de Oliveira, M. R.; Palma, D.; Toxicol. In Vitro 2011, 25, 2054.

29. Lopes, N. P.; Stark, C. B. W.; Hong, H.; Gates, P. J.; Staunton, J. Z.; Analyst 2001, 126, 1630.

30. Demarque, D. P.; Crotti, A. E. M.; Vessecchi, R.; Lopes, J. L. C.; Lopes, N. P.; Nat. Prod. Rep. 2016, 33, 432.

31. Rees, D. C.; J. Heterocycl. Chem. 1990, 27, 147.

32. https://www.ich.org/products/guidelines/multidisciplinary/ article/multidisciplinary-guidelines.html, accessed in February 2019.

33. Derek Nexus, version 6.0; Lhasa Limited, Leeds, United Kingdom, 2017; Sarah Nexus, version 3.0; Lhasa Limited, Leeds, United Kingdom, 2017.

34. Kem, W. R.; J. Org. Chem. 1992, 57, 2392.

35. Holmqvist, S.; Johansson, A.; Svensson, A.; Von Unge, S.; US pat. WO2006137790A1 2006.

36. Descôteaux, C.; Brasseur, K.; Leblanc, V.; Asselin, E.; Bérubé, G.; Med. Chem. 2015, 11, 717.

37. Hanser, T.; Barber, C.; Rosser, E.; Vessey, J. D.; Webb, S. J.; Werner, S.; J. Cheminf. 2014, 6, 21.

38. https://www.lhasalimited.org/publications/using-sarahnexus-effectively-intuitive-model-building-and-interpretingconfidence/4268, accessed in February 2019.

39. Barber, C.; Cayley, A.; Hanser, T.; Harding, A.; Heghes, C.; Vessey, J. D.; Werner, S.; Weiner, S. K.; Wichard, J.; Giddings, A.; Glowienke, S.; Parenty, A.; Brigo, A.; Spirkl, H. P.; Amberg, A.; Kemper, R.; Greene, N.; Regul. Toxicol. Pharmacol. 2016, $76,7$.

40. Kenyon, M. O.; Cheung, J. R.; Dobo, K. L.; Ku, W. W.; Regul. Toxicol. Pharmacol. 2007, 48, 75. 
41. Luo, Q.; Li, Y.; Zhang, Z.; Int. J. Clin. Exp. Med. 2014, 7, 4260.

42. Paim, C. S.; Fürh, F.; Barth, A. B.; Gonçalves, C. E. I.; Nardi, N.; Steppe, M.; Schapoval, E. E. S.; Talanta 2011, 83, 1774.

43. Rystov, L.; Chadwick, R.; Krock, K.; Wang, T.; J. Pharm. Biomed. Anal. 2011, 56, 887.

44. Rao, P. S.; Ray, U. K.; Hiriyanna, S. G.; Rao, S. V.; Sharma, H. K.; Handa, V. K.; Mukkanti, K.; J. Pharm. Biomed. Anal. 2011, $56,413$.

45. Emerce, E.; Cok, I.; Degim, I. T.; Toxicol. Lett. 2015, 238, 90.

46. Zhu, Q.; Li, T.; Li, J.; Guo, M.; Wang, W.; Zhang, X.; Toxicol. Mech. Methods 2012, 22, 225.
47. Zhu, Q.; Li, T.; Wei, X.; Li, J.; Wang, W.; Drug Chem. Toxicol. 2014, 37, 311.

48. Adrion, C.; Fischer, C. S.; Wagner, J.; Gürkov, R.; Mansmann, U.; Strupp, M.; BMJ [Br. Med. J.] 2016, 352, h6816.

49. Tootoonchi, S. J. S.; Ghiasi, S.; Shadara, P.; Samani, S. M.; Fouladi, D. F.; Braz. J. Otorhinolaringol. 2016, 82, 500.

Submitted: November 6, 2018

Published online: March 1, 2019 